\title{
INTERPRETIVE SUMMARIES, AUGUST 2015
}

Evaluation of X-ray fluorescence spectroscopy as a method for the rapid and direct determination of sodium in cheese. By Stankey et al., page 5040. Cheese manufacturers need a direct and rapid method for Na detection; existing techniques overestimate the actual $\mathrm{Na}$ content in cheese when salt replacers such as $\mathrm{KCl}$ are used. We evaluated X-ray fluorescence spectroscopy (XRF) as an alternative method for $\mathrm{Na}$ detection in cheese. The equipment was calibrated using natural or process cheeses made with a range of $\mathrm{NaCl}$ or $\mathrm{KCl}$. This method successfully predicted $\mathrm{Na}$ content in both natural and process cheeses made with or without K-based replacement salts.

http://dx.doi.org/10.3168/jds.2014-9055.

Milk skimming, heating, acidification, lysozyme, and rennet affect the pattern, repeatability, and predictability of milk coagulation properties and of curd-firming model parameters: A case study of Grana Padano. By Stocco et al., page 5052. The quality and coagulation aptitude of milk are important for the final features of partially skimmed, long-ripening hard cheeses, like Grana Padano Protected Denomiantion of Origin cheese. Variations in laboratory procedures to imitate Grana Padano cheese making resulted in different patterns, repeatability, and correlations of milk coagulation properties and curdfirming model parameters. Predictability of the cheesemaking aptitude of milk samples for Grana production using the standard lactodynamographic procedure was fair to good for different traits, but never very high, showing that maximum informative value could be attained by adopting a specific, more complex, and laborintensive procedure.

http://dx.doi.org/10.3168/jds.2014-9146.

Chemical characterization of milk after treatment with thermal (HTST and UHT) and nonthermal (turbulent flow ultraviolet) processing technologies. By Cappozzo et al., page 5068. This study showed that continuous flow ultraviolet (UV) processing, whether used alone or in combination with high-temperature, short-time (HTST) treatment, did not cause significant chemical changes compared with raw and heat-treated milk with regard to the proximate analysis (total fat, protein, carbohydrates, moisture or ash), fatty acid profile, lipid oxidation, and protein profile. There was some loss of vitamins D and A after all treatments that included continuous turbulent flow UV processing, but this loss was comparable to that found with traditional thermal processing, such as HTST and UHT. Thus, chemical characterization of milk composition showed that turbulent flow UV technology could be used as alternative nonthermal method for extending the shelf life of raw and pasteurized milks.

http://dx.doi.org/10.3168/jds.2014-9190.

Isolation and mode of action of bacteriocin BacC1 produced by nonpathogenic Enterococcus faecium C1. By Goh and Philip, page 5080. The purpose of this study was to identify, characterize, and evaluate a new bacterial strain as a potential probiotic. We evaluated various properties that help make a bacterial strain successful as a probiotic, including the identification and characterization of an antimicrobial compound and genome sequencing with evaluation of virulence factors.

http://dx.doi.org/10.3168/jds.2014-9240.

Mining for sensitive and reliable species-specific primers for PCR for detection of Cronobacter sakazakii by an informatics approach. By Qiming et al., page 5091. Cronobacter sakazakii can cause human infection and the fatality rate can be up to $80 \%$. Although several studies have reported PCR asssays for identifying C. sakazakii in the genus, reports regarding assay sensitivity and specificity and applications for food testing are lacking. In this study, specific molecular targets were screened from the genome sequence of C. sakazakii and a new PCR method was developed. The developed primers were more specific, sensitive, and reliable than those used and reported previously. http://dx.doi.org/10.3168/jds.2015-9304.

Dietary Maillard reaction products and their fermented products reduces cardiovascular risk in animal model. By Oh et al., page 5102. In this study, Maillard reaction products (MRP) and fermented MRP were investigated for their effects on antioxidant activity and the promotion of cardiovascular health in mice and rats. The antioxidant activity and protective effects on cardiovascular health of Maillard-reacted sodium caseinate (cMRP) and fermented cMRP were determined by related messenger RNA expression and serum profile. Moreover, Maillard-reacted whey protein concentrate (wMRP) and wMRP fermented by Lactobacillus gasseri H10 dramatically prolonged tail bleeding times and protected mice from the acute pulmonary thromboembolism. In particular, effects were promoted by fermentation of MRP. Consequently, dietary MRP and fermented MRP to reduce cholesterol levels and cell damage suggest that they might be of preventive and therapeutic benefit to humans with cardiovascular disease.

http://dx.doi.org/10.3168/jds.2015-9308. 
Characterization of angiotensin-converting enzyme inhibitory activity of fermented milk produced by Lactobacillus helveticus. By Chen et al., page 5113. Hypertension affects up to $30 \%$ of the global adult population. The fermented milks produced by some Lactobacillus helveticus strains possess strong angiotensin-converting enzyme (ACE)-inhibitory activity, and thus might help to reduce blood pressure. By screening the ACE-inhibitory activity of milks fermented by 59 traditional fermented food-origin strains, we identified a novel microbial resource, IMAU80782, with stable high ACE-inhibitory activity, that was the most suitable candidate among those tested for developing functional hypotensive dairy products. Comparing the fermented milk metabolomes, we further identified 6 potential hypotensive peptides that merit further characterization. http://dx.doi.org/10.3168/jds.2015-9382.

Minor and potentially toxic trace elements in milk and blood serum of dairy donkeys. By Fantuz et al., page 5125. Donkey milk has been proposed as a food for consumers sensitive to bovine milk. This paper provides data on minor and potentially toxic elements in donkey milk and their relationship with respective levels in blood serum. Under our experimental conditions, in agreement with the low levels in drinking water and feedstuffs, the concentration of potentially toxic elements in donkey milk was very low and did not raise health concerns for human consumption. http://dx.doi.org/10.3168/jds.2015-9404.

Effect of jenny milk addition on the inhibition of late blowing in semihard cheese. By Cosentino et al., page 5133. Jenny milk is an important source of lysozyme, a well-known natural antimicrobial agent that may contribute to the inhibition of bacterial growth in cheese, thus controlling late blowing defects. To verify this hypothesis, we added jenny milk to cow milk during cheese making. The effect of jenny milk addition was evaluated on semihard cheeses through physical, chemical, microbiological analyses. Moreover, 80 consumers evaluated the acceptability of cheese. We observed a progressive reduction of the occurrence of late blowing defects in cheese with increasing addition of jenny milk during cheese making. Moreover, the addition of jenny milk did not affect the acceptability of the product, as consumers found no difference among cheeses concerning sensorial aspects.

http://dx.doi.org/10.3168/jds.2015-9458.

Molecular identification and quantification of lactic acid bacteria in traditional fermented dairy foods of Russia. By Yu et al., page 5143. This report focused on the exploitation of lactic acid bacteria $(\mathrm{LAB})$ resources and analysis of $\mathrm{LAB}$ composition in Russian traditional fermented dairy foods by culture and quantitative PCR. A total of 599 LAB were obtained from 159 samples; the identified LAB belonged to 7 genera and 30 species. The research contributes to further studies of probiotic strain selection and starter culture design for the industrial production of traditional fermented milk.

http://dx.doi.org/10.3168/jds.2015-9460.

Mechanisms of Clostridium tyrobutyricum removal through natural creaming of milk: A microscopy study. By D'Incecco et al., page 5164. Removal of Clostridium tyrobutyricum from raw milk is essential to avoid the late blowing defect in Grana Padano and Parmigiano-Reggiano. This removal is partially achieved by natural creaming, as most of bacteria, somatic cells, and spores rise to the top of the milk, together with the fat globules, and are discharged with cream. The interactions between $C l$. tyrobutyricum and fat globules during creaming were investigated at the structural and ultrastructural level to elucidate adhesion mechanisms, knowledge of which could indicate new technological approaches for complete eradication of dangerous bacterial spores of $C l$. tyrobutyricum from cheese.

http://dx.doi.org/10.3168/jds.2015-9526.

Strain diversity and phage resistance in complex dairy starter cultures. By Spus et al., page 5173. We found extreme differences in bacteriophage resistance among highly related strains in a complex dairy starter. Our attempt to analyze the role of bacteriophages by designing simple defined blends of well-characterized strains resulted in unstable composition of blends upon propagation in milk. Moreover, we found loss of the proteolytic activity of initially proteolytic strains. We confirmed the role of the individual resistance of strains to phage predation as a factor shaping diversity in complex dairy starter culture at the level of genetic lineages.

http://dx.doi.org/10.3168/jds.2015-9535.

Genetic relationships among Enterococcus faecalis isolates from different sources as revealed by multilocus sequence typing. By Chen et al., page 5183. Some Enterococcus faecalis strains can be used in food production, whereas others are pathogenic. It is important, therefore, to analyze the relationship between food-source isolates with pathogenic isolates. In this study, we compared relationships of 39 isolates from Chinese traditional food products with 4 published isolates from other sources, including humansource isolates. The isolates from dairy sources were clustered together. However, the relationship between isolates from acidic gruel and one isolate from a human source was also close.

http://dx.doi.org/10.3168/jds.2015-9571. 
Evaluation of testing strategies to identify infected animals at a single round of testing within dairy herds known to be infected with Mycobacterium avium ssp. paratuberculosis. By More et al., page 5194. In herds infected with Johne's disease, control strategies rely on management changes, to limit transmission, and testing, to allow infected animals to be removed. However, testing is problematic because false negatives (infected animals that test negative) are common. In this study, we used a modelling approach to evaluate the quality of different testing strategies, by measuring effectiveness, cost, and cost-effectiveness, the latter being either the cost of testing only or all costs associated with each infected animal that is correctly identified and removed. The model results highlight the diagnostic difficulties faced.

http://dx.doi.org/10.3168/jds.2014-8211.

Milk fatty acids as possible biomarkers to diagnose hyperketonemia in early lactation. By Jorjong et al., page 5211. Milk is an interesting body fluid to monitor metabolic disorders in dairy cows because monitoring is noninvasive and sampling is convenient. The milk fat $\mathrm{C} 18: 1$ cis-9-to-C15:0 ratio was identified as a potential indicator for diagnosis and prediction of hyperketonemia during the first $8 \mathrm{wk}$ in lactation. However, routine analysis of C15:0 remains a major challenge.

http://dx.doi.org/10.3168/jds.2014-8728.

Evaluating the effect of Focus Farms on Ontario dairy producers' knowledge, attitudes, and behavior toward control of Johne's disease. By Roche et al., page 5222. This study evaluated an agricultural extension program, Ontario Focus Farms (FF), aimed at changing producer behavior for Johne's disease (JD) control. The proportion of FF participants who reported making at least one on-farm change was significantly higher than control respondents. These changes significantly reduced on-farm risk scores for JD spread. Although producers held positive attitudes towards JD control, and felt pressure to make changes, they questioned their ability to effectively control JD on their farms. This paper describes the success of an agricultural extension approach and identifies key areas for improvement to further influence on-farm change. http://dx.doi.org/10.3168/jds.2014-8765.

Habituation of dairy heifers to milking routine-Effects on human avoidance distance, behavior, and cardiac activity during milking. By Kutzer et al., page 5241. During the periparturient period, transition heifers experience changes in housing conditions and management procedures. To ease this transition, we conducted training sessions in the milking parlor on 5 Swiss dairy farms with heifers before the onset of lactation. Control heifers received no training.
Results on stepping, kicking, and expressive behavior recorded during milking indicated that the training regimen habituated heifers to some extent to the milking routine. In addition, human avoidance distance in heifers, initially showing a high level of fear of humans, decreased over time. However, training did not influence milk production.

http://dx.doi.org/10.3168/jds.2014-8773.

Production and physiological responses of heatstressed lactating dairy cattle to conductive cooling. By Perano et al., page 5252. Cow waterbeds continuously cooled with chilled water can be used to relieve heat stress in dairy cattle. A heat-stressed dairy cow spends extra energy to maintain body temperature, leading to reduced milk production. The effects of heat stress cost the US dairy industry an estimated 4 to $7 \%$ revenue loss per year. In this study, conductive cooling decreased rectal temperature by $1.0^{\circ} \mathrm{C}$, decreased respiration rate by 18 breaths/min, increased milk yield by $5 \%$, and increased dry matter intake by $14 \%$. Thus, conductive cooling may be a useful tool to alleviate heat stress in dairy cows.

http://dx.doi.org/10.3168/jds.2014-8784.

Machine learning algorithms for the prediction of conception success to a given insemination in lactating dairy cows. By Hempstalk et al., page 5262. Decision support tools that provide estimates of the likelihood of conception to a future insemination for a cow could be useful for producers in deciding if a high value (e.g., sexed semen) or low value (e.g., beef semen) should be used. This study used herd- and cow-level factors provided to machine learning algorithms in an attempt to predict the likelihood of conception success. Although the accuracy of the prediction in general was deemed to be fair across the entire spectrum of predicted probabilities, the developed model could be used to predict cows most likely to establish pregnancy. http://dx.doi.org/10.3168/jds.2014-8984.

Carryover of bovine leukemia virus antibodies in samples from shared milk meters. By Nekouei et al., page 5274. Screening for infectious disease of cattle using milk from dairy herd improvement (DHI) sampling is very convenient. However, when samples from shared milk meters are used, carryover of antibodies or other diagnostic targets can complicate the interpretation of the test results. This study determined that the effect of bovine leukemia virus antibody carryover was significant if low-titer (e.g. negative) cows were preceded by high-titer cows at the same meters. After adjusting the cut-point of our ELISA test, a retest on suspicious results was recommended to optimize the performance of the test (reducing the false-positive rate). http://dx.doi.org/10.3168/jds.2014-9036. 
Examination of weekly mammary parenchymal area by ultrasound, mammary mass, and composition in Holstein heifers reared on 1 of 3 diets from birth to 2 months of age. By Esselburn et al., page 5280. In this study, area of mammary parenchyma (PAR) present in heifers reared on 1 of 3 diets was examined by ultrasound (US) once weekly from birth until 2 mo of age. Mammary mass and composition measurements were obtained at 2 mo of age and were compared with US measures. No dietary effects on US and mammary measures were observed in the present study. Ultrasound is an effective, minimally invasive tool for measuring PAR size. Area measurements obtained by ultrasound were highly correlated with tissue mass at 2 mo of age. Additionally, ultrasound examination enables observation of PAR growth over time in the same animals.

http://dx.doi.org/10.3168/jds.2014-9061.

Evaluation of the efficacy of intramuscular versus intramammary treatment of subclinical Streptococcus agalactiae mastitis in dairy cows in Colombia. By Reyes et al., page 5294. The present study evaluated the efficacy of intramuscular and intramammary treatments for Streptococcus agalactiae subclinical mastitis in a randomized controlled trial. Efficacy was evaluated by bacteriological cure risk for an initial treatment and retreatment of refractory cases. Treatment programs, in conjunction with other management strategies, can play a substantial role in reducing prevalence of Streptococcus agalactiae, and these results suggest that the overall cure risk for the intramammary product was significantly greater than the intramuscular product.

http://dx.doi.org/10.3168/jds.2014-9199.

Prediction of parturition in Holstein dairy cattle using electronic data loggers. By Titler et al., page 5304. Under field conditions, calving personnel routinely monitor the appearance of the amniotic sac (AS) or feet of the calf outside the vulva as signs of imminent birth. In practice, however, the frequency of observation (calving personnel walking the pen and actually observing cows every $1 \mathrm{~h}$ ) is critical to determine the onset of the AS or feet of the calf outside the vulva to identify cows in need of assistance (dystocia) and reduce the prevalence of stillbirth. The present study provided evidence that cows close to calving, regardless of parity, showed a distinct behavioral activity approximately $6 \mathrm{~h}$ before birth of a calf. Therefore, development of monitoring systems that can predict the time of parturition before the appearance of imminent signs of birth (AS or feet of the calf) would enable dairy producers and their personnel to implement a precision calving management program to effectively reduce calving-related problems due to late or no interventions. http://dx.doi.org/10.3168/jds.2014-9223.
Changes in nutrient mass balances over time and related drivers for $\mathbf{5 4}$ New York State dairy farms. By Soberon et al., page 5313. Of 54 New York State dairy farms that evaluated their annual wholefarm nitrogen, phosphorus, and potassium nutrient mass balance (NMB) for 4 to $6 \mathrm{yr}, 63$ to $76 \%$ reduced NMB over time, increasing nutrient use efficiency and reducing the farm's environmental footprint. The reduced NMB primarily reflected changes in purchased feed. In addition to gaining in nutrient use efficiency, 55 to $61 \%$ of farms that reduced their NMB per hectare also increased milk production, becoming increasingly cost efficient. We conclude that annual NMB assessments can aid in evaluation and implementation of practices that make farms more environmentally and economically sustainable over time.

http://dx.doi.org/10.3168/jds.2014-9236.

A survey of Australian dairy farmers to investigate animal welfare risks associated with increasing scale of production. By Beggs et al., page 5330. A farmer survey showed that as Australian dairy herds increase in size, some risk factors for adverse animal welfare outcomes also increase, such as having more cows per labor unit and higher levels of grain feeding. However, we found no increase in reported disease or cow contentment levels in larger herds. This may be because larger herds have greater capacity for strategies such as better training and education of staff, routine veterinary herd health visits, separate milking of the main herd and the sick cows, transition diets before calving, and written protocols for treatment of disease.

http://dx.doi.org/10.3168/jds.2014-9239.

A proteomic perspective on the changes in milk proteins due to high somatic cell count. By Zhang et al., page 5339. In this study, we compared changes in milk proteins from cows with high somatic cell count (SCC) compared with those from healthy cows by using proteomics techniques. Not only immune-related proteins, but also proteins related to other biological functions changed significantly in concentration. Prostaglandin-H2 D-isomerase (PTGDS) was found to linearly correlate with SCC and thus could be an effective biomarker for the SCC as an indicator for quality of bulk milk.

http://dx.doi.org/10.3168/jds.2014-9279.

Assessment of visceral pain associated with metritis in dairy cows. By Stojkov et al., page 5352. Inflammation of the uterus (metritis) is common in dairy cows following calving. Clinicians use palpation to assess the pain responses. We assessed back arch and heart rate variability as visceral pain responses during rectal palpation with and without uterine palpation in 
healthy and metritic cows. Cows with metritis showed a more pronounced back arch during palpation, indicating that this condition is painful. Heart rate variability measures indicated that rectal palpation with uterine palpation was more painful than rectal palpation without uterine palpation.

http://dx.doi.org/10.3168/jds.2014-9296.

Perspective on calf and mammary gland development through changes in the bovine milk proteome over a complete lactation. By Zhang et al., page 5362. Milk contains all the nutrients for the growth and development of the neonate. However, milk composition is not constant over lactation. In this study, we investigated changes in the milk proteome over a complete lactation by using shotgun proteomics. Immune-related proteins, enzymes, as well as proteins related to lipid synthesis and transport changed as lactation advanced. In addition, these proteins change differently over lactation. The changes of proteins with different biological functions reflect not only the changing needs of calves but also the development and protection of the mammary gland over lactation.

http://dx.doi.org/10.3168/jds.2015-9342.

The relationship between fatty acid profiles in milk identified by Fourier transform infrared spectroscopy and onset of luteal activity in Norwegian dairy cattle. By Martin et al., page 5374. Dry film Fourier transform infrared technology can be used to successfully identify the composition of milk fatty acids after freezing. Milk fatty acid analyses in the fourth week of lactation can predict whether onset of luteal activity occurred early ( $\leq 21$ days in milk) or late ( $>21$ days in milk) in Norwegian Red dairy cows. This study showed that, when these data are made available on farm, they can improve cow management decision making.

http://dx.doi.org/10.3168/jds.2015-9343.

The effect of transient, moderate dietary phosphorus deprivation on phosphorus metabolism, muscle content of different phosphorus-containing compounds, and muscle function in dairy cows. By Grünberg et al., page 5385. Hypophosphatemia is a common finding in periparturient and anorectic cattle and has been implicated as a possible cause of persistent recumbency in fresh cows. In the present study, we investigated the effect of transient dietary $\mathrm{P}$ deprivation on muscle function and muscle phosphorus content. Results of this study provide an improved understanding of the role of phosphorus for muscle function in cattle.

http://dx.doi.org/10.3168/jds.2015-9357.
Administration of prostaglandin $F_{2 \alpha} 14 \mathrm{~d}$ before initiating a G6G or a G7G timed-artificial insemination protocol increased circulating progesterone prior to artificial insemination and reduced pregnancy loss in multiparous Holstein cows. By Dirandeh et al., page 5414. We investigated the effect of a prostaglandin $\mathrm{F}_{2 \alpha}\left(\mathrm{PGF}_{2 \alpha}\right)$ treatment 14 $\mathrm{d}$ before the initiation of a $\mathrm{G} 6 \mathrm{G}$ or $\mathrm{G} 7 \mathrm{G}$ timed artificial insemination (AI) protocol on ovarian response, plasma progesterone concentrations, and pregnancy status in multiparous Holstein cows. Administration of $\mathrm{PGF}_{2 \alpha}$ increased ovulatory response to first gonadotropinreleasing hormine $(\mathrm{GnRH})$ of Ovsynch, progesterone concentrations before AI, and late embryonic and early fetal survival.

http://dx.doi.org/10.3168/jds.2015-9417.

The effects of milking frequency on insulin-like growth factor I signaling within the mammary gland of dairy cows. By Murney et al., page 5422. The effects of milking frequency on insulin-like growth factor I (IGF-I) signaling, which can influence both mammary epithelial cell number and their secretory activity, were investigated in early lactation. Udder halves were milked either 4 times a day $(4 \times)$ or once a day $(1 \times)$ for $14 \mathrm{~d}$, after which mammary tissue was analyzed. The expression of factors that are thought to suppress the effects of IGF-I within the mammary gland tissues were found to be downregulated in response to $4 \times$ milking, which suggests the potential modulation of IGF-I signaling in response to changes in milking frequency. However, activation of intracellular signaling pathways commonly thought to be stimulated by IGF-I were not influenced by increased milking frequency. Instead, a pathway associated with cell survival was more highly activated in response to $1 \times$ milking, which could account for the lack of increased apoptosis observed in these tissues in response to $1 \times$ milking. These results illustrate the complex nature of IGF-I signaling within mammary glands; the intracellular mechanisms remain unclear.

http://dx.doi.org/10.3168/jds.2015-9425.

Evaluation of propylene glycol and glycerol infusions as treatments for ketosis in dairy cows. By Piantoni and Allen, page 5429. We evaluated plasma metabolites and insulin responses to propylene glycol (PG) and glycerol (G) infusions in early lactation cows in 2 experiments. The first experiment compared $P G$ with $\mathrm{G}$ (300 $\mathrm{mL}$ each), infused in either the abomasum (A) or the reticulorumen (R). The second experiment compared PG $(300 \mathrm{~mL})$ with a combination of PG and $\mathrm{G}$ (GPG; $300 \mathrm{~mL}$ each) and $\mathrm{G}$ at 2 different doses (300 and $600 \mathrm{~mL}$ ), all infused into the R. When dosed into the R, PG is as effective a treatment as GPG at in- 
creasing plasma glucose and insulin concentrations and decreasing plasma beta-hydroxybutyrate concentration. http://dx.doi.org/10.3168/jds.2015-9476.

Short communication: Effects of Bos taurus autosome 9-located quantitative trait loci haplotypes on enzymatic mastitis indicators of milk from dairy cows experimentally inoculated with Escherichia coli. By Sørensen et al., page 5440. In an experimental setup, the effect of a pathogenspecific mastitis quantitative trait loci (QTL) on the activity of 4 milk based inflammatory enzymes was investigated. The activities of l-lactate dehydrogenase, $N$-acetyl- $\beta$-d-glucosaminidase, alkaline phosphatase, and $\beta$-glucosaminidase were measured in milk samples from cows infected with Escherichia coli. All enzymes showed a strong reaction to the $E$. coli infection and performed equally well as mastitis indicators. The results indicated differences in activities of all enzymes between cows bearing a QTL haplotype associated with either low or high susceptibility to E. coli mastitis. http://dx.doi.org/10.3168/jds.2014-9071.

Short communication: Species group-specific predictors at the cow and quarter level for intramammary infection with coagulase-negative staphylococci in dairy cattle throughout lactation. By De Visscher et al., page 5448. Factors associated with intramammary infection caused by coagulase-negative staphylococci (CNS) species were studied at the cow and quarter levels. Quarters from heifers, those from heifers and multiparous cows in third or fourth month in lactation, and those with an increasing quarter milk somatic cell count were more likely to be infected with Staphylococcus chromogenes, S. simulans, and $S$. xylosus, the CNS species previously identified as being more relevant for udder health.

http://dx.doi.org/10.3168/jds.2014-9088.

Short communication: Folates and vitamin $\mathrm{B}_{12}$ in colostrum and milk from dairy cows fed different energy levels during the dry period. By Duplessis et al., page 5454. Folate concentration of colostrum (440.3 ng/mL) was higher than folate concentration in milk at $11 \mathrm{~d}$ in milk $(93.7 \mathrm{ng} / \mathrm{mL})$ and at 39 $\mathrm{d}$ in milk $(78.4 \mathrm{ng} / \mathrm{mL})$ but was not affected by levels of energy fed during the dry period. Vitamin $\mathrm{B}_{12}$ concentration in colostrum was higher for the controlled energy diet $(31.7 \mathrm{ng} / \mathrm{mL})$ than for the intermediate energy diet $(23.5 \mathrm{ng} / \mathrm{mL})$, whereas no treatment effect was noted for vitamin $\mathrm{B}_{12}$ concentration in milk (3.8 and $3.2 \mathrm{ng} / \mathrm{mL}$ at 11 and $39 \mathrm{~d}$ in milk, respectively). http://dx.doi.org/10.3168/jds.2015-9507.

Technical note: Intraobserver, interobserver, and test-retest reliabilities of an assessment of vaginal discharge from cows with and without acute puerperal metritis. By Sannmann and Heuwieser, page 5460. Vaginal discharge of cows postpartum is commonly assessed to distinguish cows with acute puerperal metritis from healthy cows. The diagnostic value of an assessment of color, smell, and viscosity of vaginal discharge, however, is unknown. Our study with 15 investigators evaluating 6 vaginal discharge 10 times revealed only slight to moderate reliabilities concerning the subjective evaluation of vaginal discharge.

http://dx.doi.org/10.3168/jds.2014-9169.

The role of solid feed amount and composition and of milk replacer supply in veal calf welfare. By Webb et al., page 546\%. Improving veal calf welfare requires investigating effects of solid feed amount and composition and milk replacer feeding method on behavior. Higher roughage provision, but not concentrate, increased rumination and decreased abnormal oral behaviors. Ad libitum long straw on top of a typical veal diet resulted in fewer abnormal behaviors and more rumination. Tongue playing was related to both roughage amount and milk replacer feeding method, suggesting 2 separate motivations (i.e., rumination and sucking) underlying the development of this behavior.

http://dx.doi.org/10.3168/jds.2014-8547.

The effects of a garlic oil chemical compound, propyl-propane thiosulfonate, on ruminal fermentation and fatty acid outflow in a dual-flow continuous culture system. By Foskolos et al., page 5482. Essential oil compounds are proposed as alternative growth promoters in animal feeds since the ban of antibiotic use in the European Union. Garlic oil has several antimicrobial compounds that affect ruminal fermentation. Propyl-propane thiosulfonate is a recently purified stable organosulfurate compound of garlic. At optimal doses, it improves ruminal fermentation by increasing propionate concentration and the outflow of unsaturated fatty acid, and reducing the outflow of trans-10,cis-12 conjugated linoleic acid, which has been associated with the induction of milk fat depression in dairy cattle.

http://dx.doi.org/10.3168/jds.2014-8674.

The effect of buffering dairy cow diets with limestone, calcareous marine algae, or sodium bicarbonate on ruminal $\mathrm{pH}$ profiles, production responses, and rumen fermentation. By Cruywagen et al., page 5506. Three high-concentrate and potentially acidotic diets were formulated in which calcareous marine algae (calcified remains of the seaweed Lithothamnium calcareum) was compared with limestone (control) and sodium bicarbonate plus limestone. The buffer treatments, and especially the calcareous marine algae, alleviated rumen acidity and shortened the duration below pH 5.5. Buffer inclusion had a positive effect on milk production and milk composition. 
Calcareous marine algae, at a level of $90 \mathrm{~g} /$ cow per day, had a greater effect on rumen $\mathrm{pH}$, milk production, and efficiency of feed conversion into milk than sodium bicarbonate at a level of $180 \mathrm{~g} / \mathrm{cow}$ per day. http://dx.doi.org/10.3168/jds.2014-8875.

The effect of high and low levels of supplementation on milk production, nitrogen utilization efficiency, and milk protein fractions in latelactation dairy cows. By Reid et al., page 5529. In temperate northern European countries, grass is the cheapest feed for dairy cows. In the autumn, grass availability can be limited and diets need to be supplemented to meet the nutritional requirements of dairy cows. This study investigated the use of different levels of baled silage and concentrate as supplementation to a grass-based diet. The study showed that offering concentrate increased milk yield and milk solids yield compared with offering grass silage as supplementation. High quantities of supplementation reduced milk true protein concentration, suggesting a grass-only diet may give rise to milk that is better suited for processing. http://dx.doi.org/10.3168/jds.2014-9016.

The effect of age at separation from the dam and presence of social companions on play behavior and weight gain in dairy calves. By Valníčková et al., page 5545. This paper investigated whether staying with mother after birth (as opposed to immediate separation) and living in groups (as opposed to individual housing) enhances play behavior and promotes growth. Both initial housing with mother and later group-housing promoted growth. Play was enhanced in group-housed calves. Individually housed calves played a lot when exposed to companions, demonstrating their play deprivation. In conclusion, mother and companions improve welfare and performance of dairy calves. http://dx.doi.org/10.3168/jds.2014-9109.

Modeling the trade-off between diet costs and methane emissions: A goal programming approach. By Moraes et al., page 555\%. An optimization model was developed to jointly minimize diet costs and methane emissions from livestock. The model identifies a set of diets that generate various amounts of methane at different costs. The trade-off between minimizing diet costs and mitigating methane emissions was explored with the formulation of diets comprising different feeds and with varying nutrient composition. Model solutions give the decision maker the opportunity to choose a diet that achieves a desired trade-off based on availability and costs of feeds and on environmental policy regulations. An application of the model is also presented.

http://dx.doi.org/10.3168/jds.2014-9138.
Pyrosequencing reveals shifts in the bacterial epimural community relative to dietary concentrate amount in goats. By Wetzels et al., page 5572. Feeding of large amounts of concentrates in high-producing ruminants is important to meet their demands of energy and nutrients for production. However, this feeding strategy can also shift the rumen conditions to an acidic state, affecting the composition of rumen microbiota. Indeed, the results of the present study demonstrated that excessive barley feeding causes pronounced changes in the microbial community attached to the rumen wall, with potential health implications in goats.

http://dx.doi.org/10.3168/jds.2014-9166.

Effect of feeding 25-hydroxyvitamin $\mathrm{D}_{3}$ with a negative cation-anion difference diet on calcium and vitamin d status of periparturient cows and their calves. By Weiss et al., page 5588. Hypocalcemia is a major health concern in peripartum dairy cows. Feeding anionic diets often reduces hypocalcemia but additional dietary strategies are needed. We hypothesized that feeding $25-(\mathrm{OH}) \mathrm{D}_{3}$ compared with vitamin $\mathrm{D}_{3}$ would increase the concentrations of the active form of vitamin D in serum and colostrum, which would improve calcium status of the cow and vitamin $\mathrm{D}$ status of the calf. Supplementation of $25-(\mathrm{OH}) \mathrm{D}_{3}$ did increase vitamin $\mathrm{D}$ status of the cow and her calf. However, it did not enhance calcium status of the cow, and prevalence of clinical and subclinical hypocalcemia were nonsignificantly increased.

http://dx.doi.org/10.3168/jds.2014-9188.

Effects of dietary fat on fertility of dairy cattle: A meta analysis and meta-regression. By Rodney et al., page 5601. This meta-analysis of 17 studies containing 26 comparisons explored the effects of including oilseeds, calcium salts of fatty acids, tallow, conjugated linoleic acids, and prills on reproduction. Overall proportion of cows pregnant was increased by $27 \%$ when fats were fed in the transition period, but individual fat groups did not increase the proportion. Calving to pregnancy interval also tended to be lower when fats were fed.

http://dx.doi.org/10.3168/jds.2015-9528.

Effects of solid feed level and roughage-toconcentrate ratio on ruminal drinking and passage kinetics of milk replacer, concentrates, and roughage in veal calves. By Berends et al., page 5621. For more accurate diet formulation in veal calves, quantitative insight into ruminal drinking and passage kinetics of dietary components through the gastrointestinal tract is needed. We investigated the effects of solid feed level and roughage-to-concentrate ratio on ruminal drinking and passage kinetics of milk replacer, 
concentrates, and roughage. Although ruminal drinking was substantial, passage kinetics of milk replacer were unaffected by solid feed level and composition. Increasing solid feed intake increased rumen fractional passage rates of concentrate and roughage as well as rumen volume.

http://dx.doi.org/10.3168/jds.2015-9367.

Effect of feeding heat-treated colostrum on risk for infection with Mycobacterium avium ssp. paratuberculosis, milk production, and longevity in Holstein dairy cows. By Godden et al., page 5630. A randomized controlled field trial investigated the effect of feeding heat-treated (HT) colostrum on long-term health and performance. Newborn heifer calves were fed $3.8 \mathrm{~L}$ of fresh $(\mathrm{n}=434)$ or heat-treated $(\mathrm{n}=490)$ colostrum within $2 \mathrm{~h}$ of birth. After reaching adulthood, study animals were tested once annually for 3 years for infection with Mycobacterium avium ssp. paratuberculosis (MAP), and lactation records of milk production and death or culling events were collected. The study found no benefit of feeding HT colostrum on long-term outcomes including risk for transmission of MAP, milk production, and longevity within the herd. http://dx.doi.org/10.3168/jds.2015-9443.

Brown midrib corn shredlage in diets for highproducing dairy cows. By Vanderwerff et al., page 5642. A novel method of harvesting whole-plant corn silage, shredlage, may increase kernel processing and physically effective fiber in whole-plant corn silage. Brown midrib corn shredlage was compared with conventional-processed brown midrib corn silage or conventional-processed brown midrib corn silage plus chopped alfalfa hay for effects on intake, lactation performance, and starch and fiber digestibility in dairy cows. Feeding shredlage improved milk yield during 6 of the 14 wk of the study and starch digestibility, but not fiber digestibility or physically effective fiber, as assessed by differences in rumination activity and milk fat percentage.

http://dx.doi.org/10.3168/jds.2015-9543.

Dietary fish oil supplements depress milk fat yield and alter milk fatty acid composition in lactating cows fed grass silage based diets. By Kairenius et al., page 5653. The potential of dietary fish oil (FO) supplements to enrich 20:5n-3 and 22:6n-3 in milk and the effects on milk fat yield and composition were examined. Increases in FO from 0 to 300 $\mathrm{g} / \mathrm{d}$ increased 20:5n-3 and 22:6n-3 in milk several-fold, changes accompanied by increases in cis-9,trans-11 conjugated linoleic acid and 16- to 22-carbon trans fatty acid concentrations. Fish oil progressively lowered dry matter intake, energy-corrected milk yield, and milk fat content. Decreases in fat synthesis to FO were independent of milk trans-10,cis-12 conjugated linoleic acid content or milk fat melting point, but negatively related to 18:0 and positively associated with milk cis-11 18:1, trans-10 18:1, and trans 20- and 22-carbon fatty acid concentrations.

http://dx.doi.org/10.3168/jds.2015-9548.

Replacing dietary soybean meal with canola meal improves production and efficiency of lactating dairy cows. By Broderick et al., page 5672. We compared feeding equal crude protein (CP) from soybean meal, canola meal, or canola meal plus soybean meal to lactating Holstein cows at low or high dietary CP (about 15 or $17 \% \mathrm{CP}$ ). Half of the cows also received rumen-protected Met plus Lys. Rumenprotected amino acids (AA) increased intake without affecting production. Higher dietary $\mathrm{CP}$ increased fat yield but also elevated milk urea N (MUN) and urinary $\mathrm{N}$ excretion. Replacing soybean meal with canola meal increased intake and yields of milk, energy-corrected milk and protein and reduced MUN and urinary $\mathrm{N}$ excretion. At $15 \% \mathrm{CP}$, canola meal plus soybean meal lowered MUN versus soybean meal but did not improve $\mathrm{N}$-utilization as much as canola meal alone. Replacing soybean meal with canola meal improved production and N-efficiency in lactating dairy cows at both 15 and $17 \%$ dietary CP.

http://dx.doi.org/10.3168/jds.2015-9563.

Ruminal degradation of quercetin and its influence on fermentation in ruminants. By Berger et al., page 5688. The flavonol quercetin is a secondary plant metabolite well known for its health-promoting effects. Because of fermentation processes in the forestomachs of ruminants, however, quercetin is exposed to microbial degradation, which in turn affects its bioavailability. We investigated the ruminal degradation of quercetin and determined some of its microbial metabolites in vitro. To evaluate any negative effect of quercetin on fermentation processes, we also investigated its influence on in vitro gas production and on in vivo ruminal volatile fatty acid (VFA) production. Results showed fast and extensive microbial degradation of quercetin by ruminal microorganisms. Neither in vitro total gas and methane production nor in vivo production of VFA was influenced by quercetin. http://dx.doi.org/10.3168/jds.2015-9633.

Feeding fat from distillers dried grains with solubles to dairy heifers: I. Effects on growth performance and total-tract digestibility of nutrients. By Anderson et al., page 5699. The objective of this study was to determine if feeding fat from distillers dried grains with solubles (DDGS) to dairy heifers affected growth performance and total-tract digestibility of nutrients. Holstein heifers were fed diets containing soybean products with ground corn, low-fat DDGS with ground corn, or high-fat traditional DDGS for 24 wk. 
Digestibilities of crude protein and neutral detergent fiber were greater for the high-fat DDGS diet compared with the other diets, but dry matter and organic matter digestibilities were similar. Utilizing fat from DDGS in replacement of starch as a dietary energy source did not affect growth performance.

http://dx.doi.org/10.3168/jds.2014-9162.

Feeding fat from distillers dried grains with solubles to dairy heifers: II. Effects on metabolic profile. By Anderson et al., page 5709. Our objective was to determine if feeding fat from distillers dried grains with solubles (DDGS) to dairy heifers affected metabolic profile and onset of puberty. Holstein heifers were fed diets containing soybean products with ground corn, low-fat DDGS with ground corn, or highfat traditional DDGS for $24 \mathrm{wk}$. Most metabolites and metabolic hormones were similar, but plasma cholesterol and total fatty acids were increased by feeding fat from DDGS. Not all heifers reached puberty by the end of the feeding period, but the limited results indicate that feeding fat from DDGS may decrease the age at which puberty is reached.

http://dx.doi.org/10.3168/jds.2014-9163.

Short communcation: Feeding fat from distillers dried grains with solubles to dairy heifers: III. Effects on posttrial reproductive and lactation performance. By Anderson et al., page 5720. Our objective was to determine if feeding fat from distillers dried grains with solubles (DDGS) to dairy heifers during the prepubertal growth period affected reproductive and lactation performance. Holstein heifers were fed diets containing soybean products with ground corn, low-fat DDGS with ground corn, or high-fat traditional DDGS from 4.5 to 10.5 mo of age. Posttrial reproductive performances were similar among treatments. Milk yield for the first 4 mo of lactation was maintained by heifers fed the traditional DDGS and greater in heifers fed the low-fat DDGS diet compared with heifers fed the corn and soybean diet.

http://dx.doi.org/10.3168/jds.2014-9164.

Short communication: The effect of 4 antiseptic compounds on umbilical cord healing and infection rates in the first 24 hours in dairy calves from a commercial herd. By Robinson et al., page 5726. Federal regulations regarding the sale and storage of $7 \%$ iodine solutions have increased the interest in exploring the effectiveness of alternative umbilical antiseptics. There are few studies documenting the effectiveness of alternative umbilical antiseptics for dairy calves. Four antiseptic solutions (products based on $7 \%$ iodine, $4 \%$ chlorhexidine, $10 \%$ trisodium citrate, and $1,000 \mathrm{ppm}$ chlorine) were compared to determine their effect on umbilical healing and 24 -h infection rates in a field trial with dairy calves. We observed no differences between treatments, suggesting that all 4 dips tested were effective in preventing umbilical infections and permitting healing of the umbilical cord when used within 30 min of birth under clean, dry conditions. http://dx.doi.org/10.3168/jds.2014-9235.

Short communication: Use of a mixture of sodium nitrite, sodium benzoate, and potassium sorbate in aerobically challenged silages. By Knicky and Sporndly, page 5729. This study evaluated the effect on silage quality when an additive based on sodium benzoate, potassium sorbate, and sodium nitrite was used with different forage crops under difficult ensiling conditions created by low density and air ingression into the silo. The additive mixture considerably decreased yeast activity in silages, as demonstrated by reduced ethanol formation. Consequently, use of the additive mixture reduced silage losses and significantly prolonged the aerobic stability of silages. http://dx.doi.org/10.3168/jds.2015-9332.

Short communication: Noninvasive indicators to identify lactating dairy cows with a greater risk of subacute rumen acidosis. By Gao and Oba, page 5735. Lactating dairy cows markedly vary in their ability to cope with the dietary factors that predispose them to acidosis. Among 35 cows in late lactation, those with highest milk urea nitrogen concentrations (MUN) and milk fat higher than the average were selected as animals that presumably have low risk of acidosis, and cows in late lactation with lowest MUN concentrations and milk fat less than the average were selected as animals that presumably have high risk of acidosis. When these cows were fed a high-grain diet in the following lactation, low-risk cows had higher minimum and mean ruminal $\mathrm{pH}$ compared with high-risk animals. In addition, duration of rumen acidosis was shorter in low-risk cows. These results suggested that MUN and milk fat content in late-lactating cows fed a high-grain diet may be used to identify cows that have higher or lower risk of acidosis.

http://dx.doi.org/10.3168/jds.2015-9456.

\section{Hot topic: Innovative lactation-stage-dependent} prediction of methane emissions from milk midinfrared spectra. By Vanlierde et al., page 5740. Predicting the methane emissions of lactating dairy cows using readily available traits has great potential for mitigation purposes. Previous studies have shown the feasibility of using milk mid-infrared spectra to predict the emission of methane, with spectra being routinely generated in milk analysis laboratories. However, the expected relationship between methane and milk composition and therefore spectra have to be considered lactation-stage dependent. This study presents and val- 
idates an easily implementable prediction method for methane eructed by dairy cows from milk mid-infrared spectra considering the lactation stage of the animal. http://dx.doi.org/10.3168/jds.2014-8436.

Simulation, prediction, and genetic analyses of daily methane emissions in dairy cattle. By Yin et al., page 5748. Application of random regression models requires a longitudinal data structure, which generally does not exist for methane emissions of cows. Our idea for data generation combined information from daily feeding strategies and test-day indicator traits by using deterministic prediction equations and stochastic simulations. Predicted daily methane emissions showed a moderate heritability and strong correlations with productivity and female fertility. Genetic covariances also reflect auto-correlations between methane emissions and such indicator traits used in prediction equations, and imply verification of results based on real methane data in ongoing studies.

http://dx.doi.org/10.3168/jds.2014-8618.

Estimating genetic parameters for fertility in dairy cows from in-line milk progesterone profiles. By Tenghe et al., page 5763. Although milk progesterone $(\mathrm{P} 4)$ profiles have been widely accepted as valid indicators of fertility in dairy cows, their application in routine genetic evaluation schemes has been constrained by the high cost associated with collecting these measures in sufficient number of samples per cow. Until recently, methods to measure milk $\mathrm{P} 4$ level were manual and labor intensive. However, technology to measure P4 level has advanced to allow in-line systems to instantly measure milk $\mathrm{P} 4$ level. We showed that in-line $\mathrm{P} 4$ records can be used to define and explore several heritable endocrine fertility traits that can be used in genetic improvement of fertility.

http://dx.doi.org/10.3168/jds.2014-8732.

Genome-wide association study for semen production traits in Holstein-Friesian bulls. By Suchocki and Szyda, page 5774. Based on a data set of the reference bull population from genomic selection evaluation, we identified candidate genes for traits describing semen quality. Interestingly, most of them are located on chromosome X, indicating its importance in genetic determination of this trait. Because many semen quality traits undergo routine recording it is tempting to consider including the phenotypes into genetic evaluation and genomic evaluation.

http://dx.doi.org/10.3168/jds.2014-8951.
Genetic analysis of the cumulative pseudo-survival rate during lactation of Holstein cattle in Japan by using random regression models. By Sasaki et al., page 5781. Longevity is a crucial economic trait in the dairy farming industry. We used random regression models to predict the genetic parameters of the cumulative pseudo-survival rate. The results of the random regression models correlated well with the results of a proportional hazard model. The single-trait random regression model could be used for estimating the genetic parameters of survivability. Our model provides an effective method for predicting the genetic contribution to survival, which will facilitate the selection and management of dairy herds for increasing milk productivity without compromising longevity.

http://dx.doi.org/10.3168/jds.2014-9152.

Genotype by environment interactions on culling rates and 305-day milk yield of Holsteins cows in 3 US regions. By Tsuruta et al., page 5796. Termination codes for culling reasons and milk yields for Holstein cows were analyzed using genotypes, phenotypes, and pedigree in large and small herds in the Southeast, Southwest, and Northeast regions of the United States. Sires used in large and small herds were evaluated for culling rates differently in the Southwest relative to other regions. Genes responsible for culling reasons were more likely linked to milk production, especially in the Northeast. Different genomic segments can be responsible for culling reasons for cows in large and small herds in the different US regions, but major genes may be beneficial in different environments.

http://dx.doi.org/10.3168/jds.2014-9242.

A standard bacterial isolate set for research on contemporary dairy spoilage. By Trmčić et al., page 5806. Spoilage of dairy products remains a major challenge with some studies, suggesting that 25 to $30 \%$ of dairy products may be lost due to spoilage. The objective of this study was to assemble and offer a publicly available isolate set of contemporary bacterial isolates associated with the spoilage of milk and dairy products. This isolate set will provide a valuable tool for studying dairy spoilage and introduce unification and faster progress in this field of science and technology.

http://dx.doi.org/10.3168/jds.2015-9490. 